\title{
Preclinical study of mouse pluripotent parthenogenetic embryonic stem cell derivatives for the construction of tissue- engineered skin equivalent
}

\author{
Yang Rao ${ }^{1 \dagger}$, Jihong Cui ${ }^{1,2+}$, Lu Yin', Wei Liu', Wenguang Liu' ${ }^{1}$, Mei Sun ${ }^{1}$, Xingrong Yan ${ }^{1,2}$, Ling Wang ${ }^{1}$ \\ and Fulin Chen ${ }^{1,2^{*}}$
}

\begin{abstract}
Background: Embryonic stem cell (ESC) derivatives hold great promise for the construction of tissue-engineered skin equivalents (TESE). However, harvesting of ESCs destroys viable embryos and may lead to political and ethical concerns over their application. In the current study, we directed mouse parthenogenetic embryonic stem cells (pESCs) to differentiate into fibroblasts, constructed TESE, and evaluated its function in vivo.

Methods: The stemness marker expression and the pluripotent differentiation ability of pESCs were tested. After embryoid body (EB) formation and adherence culture, mesenchymal stem cells (MSCS) were enriched and directed to differentiate into fibroblastic lineage. Characteristics of derived fibroblasts were assessed by quantitative real-time PCR and ELISA. Functional ability of the constructed TESE was tested by a mouse skin defects repair model.

Results: Mouse pESCs expressed stemness marker and could form teratoma containing three germ layers. MSCS could be enriched from outgrowths of EBs and directed to differentiate into fibroblastic lineage. These cells express a high level of growth factors including FGF, EGF, VEGF, TGF, PDGF, and IGF1, similar to those of ESC-derived fibroblasts and mouse fibroblasts. Seeded into collagen gels, the fibroblasts derived from pESCs could form TESE. Mouse skin defects could be successfully repaired 15 days after transplantation of TESE constructed by fibroblasts derived from pESCs.

Conclusions: pESCs could be induced to differentiate into fibroblastic lineage, which could be applied to the construction of TESE and skin defect repair. Particularly, pESC derivatives avoid the limitations of political and ethical concerns, and provide a promising source for regenerative medicine.
\end{abstract}

Keywords: Parthenogenetic embryonic stem cells, Differentiation, Fibroblasts, Tissue-engineered skin equivalents

\section{Background}

Tissue engineering is an efficient method to construct functional skin equivalents for the treatment of skin defects resulting from trauma or tumor excision [1]. The strategy involves the combination of keratinocytes or

\footnotetext{
*Correspondence: chenfl@nwu.edu.cn

${ }^{\dagger}$ Equal contributors

'Laboratory of Tissue Engineering, College of Life Sciences, Northwest University, Taibai North Rd 229, Xi'an, Shaanxi Province 710069, People's Republic of China

${ }^{2}$ Provincial Key Laboratory of Biotechnology of Shaanxi, Northwest University, Taibai North Rd 229, Xi'an, Shaanxi Province 710069, People's Republic of China
}

(c) 2016 The Author(s). Open Access This article is distributed under the terms of the Creative Commons Attribution 4.0 International License (http://creativecommons.org/licenses/by/4.0/), which permits unrestricted use, distribution, and reproduction in any medium, provided you give appropriate credit to the original author(s) and the source, provide a link to the Creative Commons license, and indicate if changes were made. The Creative Commons Public Domain Dedication waiver (http://creativecommons.org/publicdomain/zero/1.0/) applies to the data made available in this article, unless otherwise stated.

fibroblasts with certain cell seeding scaffolds. Cells seeded into the scaffolds secrete various growth factors and extracellular matrix (ECM) proteins, which could stimulate proliferation and differentiation of adjacent epithelial tissue, and accelerate wound healing. Prepare tissueengineered skin equivalents (TESE) with autologous keratinocytes and fibroblasts would certainly be ideal. However, the process is time consuming, and several weeks are required to obtain the large cell numbers needed, which may put patients in danger of infection and dehydration. Furthermore, quality control of this customized therapeutic is difficult. Allogenic keratinocytes and 
fibroblasts for TESE could be harvested from foreskin circumcision specimens and cadaver skin. Despite the limited availability of the skin specimens for cell expansion, application of adult tissue has the risk of infectious pathogen transmission. Furthermore, these cells may lose their proliferative capacity and phenotype after extensive in-vitro passaging [2].

Embryonic stem cells (ESCs) have unlimited proliferative capacity and substantial ability to give rise to a variety of differentiated cell types [3]. In these situations, ESC derivatives are envisioned as promising candidates for tissue engineering and cell therapy $[4,5]$. Great efforts have been made to establish protocols to manipulate ESCs to differentiate into specific phenotypes for the construction of desired tissue, such as bone, cartilage, and fat tissues [6-8]. Keratinocytes and fibroblasts derived from ESCs were also used successfully to construct TESE and stimulate skin defect healing [5, 9]. However, significant political and ethical concerns exist over the application of ESCs, because most ESCs are harvested from the inner cell mass of blastocysts and the process requires the destruction of viable embryos.

Parthenogenesis refers to the embryonic development of oocytes without fertilization. Uniparental parthenogenetic embryonic stem cells (pESCs) are a specific ESC type that could be obtained from the inner cell mass of blastocysts from chemically activated oocytes [10]. Because of difficulty in normal placenta formation, parthenogenetic embryos are unable to grow into viable fetuses in primates. This characteristic allows the application of pESCs and their derivatives while avoiding the ethical and political hurdles associated with biparental ESCs. pESCs possess typical characteristics similar to ESCs, such as extensive self-renewal ability and pluripotent differentiation capacity [11]. Importantly, uniparental pESCs are histocompatible because of their homozygosity in human leukocyte antigen (HLA) genotypes, which are more readily matched to patients and might reduce the risk of immune rejection after transplantation of their differentiated derivatives [12], thus offering significant advantages for the applications of cell-based therapies. Directed differentiation studies have shown that pESCs are capable of generating multiple cell lineages including cardiomyocytes, hepatocytes, pancreatic endocrine cells, retinal pigmented epithelial cells, and neural progenitor cells $[11,13-16]$. Only one study has so far reported the application of pESC derivatives in stimulating damaged tissue repair [11].

We hypothesized that mouse pESCs could be directed to differentiate into fibroblasts for the construction of TESE. In the current experiment, after demonstrating that mouse pESCs exhibited similar fundamental properties to ESCs, we employed a stepwise approach to induce pESCs to differentiate into fibroblastic lineage. We then constructed TESE with pESC-derived fibroblasts $(\mathrm{pFs})$ and evaluated the therapeutic effect with a mouse skin defects repair model.

\section{Methods \\ Cell culture and characterization}

The C57BL/6J pESC and J1 mouse ESC lines were cultured on dishes coated with $0.1 \%(\mathrm{w} / \mathrm{v})$ gelatin (Sigma-Aldrich, St. Louis, MO, USA) and expanded in Serum-Free Clonal Grade Medium (Millipore, Billerica, MA, USA). Cells were passaged every 5 days by $1 \%$ accutase (Millipore), and observed by phase-contrast microscope (Nikon, Japan) during the process of culture.

Immunofluorescence staining was performed to detect stemness marker expression. pESCs and ESCs were plated on gelatin-coated (Sigma-Aldrich) glass cover lips and fixed by cold $4 \%$ paraformaldehyde in phosphatebuffered saline (PBS) for $30 \mathrm{~min}$, followed by washes three times with PBS and permeabilization with $0.25 \%$ Triton X-100 (Sigma-Aldrich) for $10 \mathrm{~min}$. Cells were then blocked with $10 \%$ bovine serum albumin (BSA; Sigma-Aldrich) for $45 \mathrm{~min}$ and incubated overnight at $4{ }^{\circ} \mathrm{C}$ with 1:200 diluted primary antibodies, including goat anti-OCT3/4, rabbit anti-NANOG; and mouse antiSSEA-1 (all from Santa Cruz Biotechnology, Santa Cruz, CA, USA). After three washes with PBS, the cells were incubated for $30 \mathrm{~min}$ at room temperature with fluorescein isothiocyanate (FITC)-labeled secondary antibodies (Invitrogen, Carlsbad, CA, USA). Nuclei were counterstained with 4,6'-diamidino-2-phenylindole (DAPI; Invitrogen). Images were obtained with a laser confocal microscope (FV1000; Olympus, Japan).

To confirm whether pESCs and ESCs possessed pluripotent differentiation capacity in vivo, ESCs and pESCs were dispersed using $1 \%$ accutase, and $1 \times 10^{6}$ cells were resuspended in $100 \mu$ l Dulbecco's modified Eagle's medium (DMEM; Gibco, Grand Island, NY, USA) and injected subcutaneously into nude mice. After 4 weeks, the specimens were harvested and fixed in $4 \%$ paraformaldehyde, dehydrated through a graded ethanol, embedded in paraffin, sectioned at $7 \mu \mathrm{m}$, deparaffinized and stained with hematoxylin and eosin (H\&E).

\section{Cell differentiation in embryoid bodies}

pESCs and ESCs were dispersed and resuspended in DMEM supplemented with $20 \%$ fetal bovine serum (FBS, Gibco), $50 \mathrm{U}-\mu \mathrm{g} / \mathrm{ml}$ penicillin-streptomycin (Invitrogen). Subsequently, $1 \times 10^{5}$ cells were transferred into ultra-low attachment dishes (Fisher Scientific, Pittsburgh, PA, USA) to form embryoid bodies (EBs). The medium was changed every 2 days. pESCs and ESCs were able to form EBs when cultured for 3 days, and were continuously cultured in suspension before surface antigen expression detection. EBs in suspension culture 
for 5 days were fixed in $4 \%$ paraformaldehyde, dehydrated and embedded in paraffin, sectioned at $5 \mu \mathrm{m}$, and incubated with primary antibodies at $4{ }^{\circ} \mathrm{C}$ overnight. The primary antibodies comprised mouse anti-SSEA-1, rabbit anti-CD151 and cytokeratin (Santa Cruz Biotechnology), and rat anti-CD73 (eBioscience, San Diego, CA, USA). After removal of primary antibodies with three washes with PBS, FITC-labeled secondary antibodies (Invitrogen) were added and incubated for 1 hour at room temperature. The cells were washed three times with PBS and counterstained with DAPI, observed under a laser confocal microscope.

\section{Cell differentiation during adherent culture}

EBs cultured in suspension for 5 days were plated onto $0.1 \%(\mathrm{w} / \mathrm{v})$ gelatin-coated dishes and cultured with DMEM supplemented with $20 \%$ FBS, $50 \mathrm{U}-\mu \mathrm{g} / \mathrm{ml}$ penicillinstreptomycin, $2 \mathrm{mM}$ L-glutamine (Invitrogen), 1 \% nonessential amino acids (Hyclone), $1 \% \beta$-mercaptoethanol (Sigma-Aldrich). To measure the expression of three germ layer markers, total RNA of adherently cultured EBs at different time points $(5,10$, and 15 day) was isolated using TRIzol (Life Technologies, Carlsbad, CA, USA) according to the manufacturer's instructions. Complementary DNA (cDNA) was synthesized from $1 \mu \mathrm{g}$ of the normalized RNA samples using a RevertAid ${ }^{\mathrm{mm}}$ First Strand cDNA Synthesis Kit (Thermo Fisher Scientific, Waltham, MA, USA) following the manufacturer's protocols. Relative levels of mRNA were determined from cDNA by quantitative real-time PCR with a SYBR Green PCR kit (Takara, Japan) in a total sample volume of $20 \mu \mathrm{l}$, and the samples were run in triplicate on a Bio-Rad CFX96 Real-Time PCR Detection System in accordance with the manufacturer's instructions. The primer sequences and the fragment sizes are presented in Table 1. All primers were obtained from Takara. Gapdh was used as the reference gene. Single-peak melting profiles were obtained for the amplifications, and the size of the PCR product was confirmed by agarose gel electrophoresis. Each experiment was repeated three times. The $\Delta \Delta C T$ method [17] was used to calculate relative amounts of transcripts.

\section{Enrichment of MSCs from EB outgrowths}

To enrich mesenchymal stem cells (MSCs), EBs cultured in suspension were adherently cultured as already described for 10-15 days. Cells were then cultured and expanded with MSC medium (MSCM; Lonza, Basel, Switzerland) for 5-6 passages to enrich spindle-shaped cells. Cells were passaged at a high ratio of 1:2 during expansion.

MSCs derived from pESCs and ESCs were named parthenogenetic MSCs (pMSCs) and embryonic MSCs (eMSCs), respectively. Cells were detached from culture
Table 1 Primers of three germ layer genes and the reference gene for quantitative real-time PCR

\begin{tabular}{|c|c|c|}
\hline Gene & Primers $\left(5^{\prime}-3^{\prime}\right)$ & Product (bp) \\
\hline \multirow[t]{2}{*}{ Snail } & GACCTGTGGAAAGGCCTTCTCTAGG & 170 \\
\hline & CCTGGCACTGGTATCTCTTCACATC & \\
\hline \multirow[t]{2}{*}{ Hand1 } & GCTACGCACATCATCACCATCATC & 125 \\
\hline & CAGCAGCCAGCTCTGGAAGTAAG & \\
\hline \multirow[t]{2}{*}{ Gata2 } & GCCAAAAGAGAGACTGGAGGAAGGG & 82 \\
\hline & ACACCTCCCACCTTTTAGTCACTCTG & \\
\hline \multirow[t]{2}{*}{ nestin } & GTTACCAAAGCCTCTTAGAAATGACC & 577 \\
\hline & CAGATGCAACTCTGCCTTATCCTC & \\
\hline \multirow[t]{2}{*}{ Oct3/4 } & GTGTGAGGTGGAGTCTGGAG & 182 \\
\hline & AGCCTCATACTCTTCTCGTTGG & \\
\hline \multirow[t]{2}{*}{ Afp } & CTCTGGCGATGGGTGTTTAG & 175 \\
\hline & TGCCTGGAGGTTTCGGGATT & \\
\hline \multirow[t]{2}{*}{ Gapdh } & GGTGAAGGTCGGTGTGAACG & 152 \\
\hline & CTCGCTCCTGGAAGATGGTG & \\
\hline
\end{tabular}

dishes by Accutase, collected and washed three times with ice-cold PBS, and resuspended in PBS. FITCconjugated primary antibodies (CD29, CD44, CD73; all from eBioscience) were added and incubated overnight, followed by two washes with ice-cold PBS. MSC surface antigen expressions were then tested by flow cytometry using FACS Calibur (BD Biosciences) analysis. Isotypespecific antibodies served as controls. Cells were analyzed using CellQuest software (BD Biosciences). At least $1 \times 10^{5}$ cells were analyzed, and three independent tests were performed for each experiment.

For osteogenic differentiation, pMSCs and eMSCs were cultured in osteogenic differentiation medium (DMEM supplemented with $20 \%$ FBS, $50 \mathrm{U}-\mu \mathrm{g} / \mathrm{ml}$ penicillin-streptomycin, $50 \mu \mathrm{M}$ ascorbic acid (SigmaAldrich), $10 \mathrm{mM} \beta$-glycerophosphate (Sigma-Aldrich), and $50 \mathrm{nM}$ dexamethasone (Sigma-Aldrich)) for 21 days. The medium was changed every 3 days. After 21 days, cells were fixed in $4 \%$ PBS-buffered paraformaldehyde and processed for Alizarin red S, Von Kossa staining, and reverse transcription-PCR (RT-PCR) assays for alkaline phosphates $(A l p)$ and osteocalcin $(O c n)$, to test the osteogenic differentiation.

For chondrogenic differentiation, cells were cultured in chondrogenic medium (DMEM supplemented with $20 \% \mathrm{FBS}, 50 \mathrm{U}-\mu \mathrm{g} / \mathrm{ml}$ penicillin-streptomycin, $50 \mu \mathrm{M}$ ascorbic acid, $10 \mathrm{ng} / \mathrm{ml}$ transforming growth factor- $\beta 1$ (TGF- $\beta 1$; R\&D Systems, Minneapolis, MN, USA), and $500 \mathrm{ng} / \mathrm{ml}$ insulin-like growth factor (IGF; R\&D Systems)). The medium was changed every 3 days. After 21 days, cells were processed for Safranin O staining and PCR assays for aggrecan and type II collagen (Col-II). 
For adipogenic differentiation, cells were exposed to adipogenic induction medium (DMEM supplemented with $20 \%$ FBS, $50 \mathrm{U}-\mu \mathrm{g} / \mathrm{ml}$ penicillin-streptomycin, $200 \mu \mathrm{M}$ indomethacin (Sigma-Aldrich), and $10 \mu \mathrm{g} / \mathrm{ml}$ insulin (Sigma-Aldrich)) for 14 days. The medium was changed every 3 days. Adipogenic differentiation was indicated by oil-red $\mathrm{O}$ staining of lipid droplet formation in cytoplasm and RT-PCR assays for peroxisome proliferatoractivated receptor gamma (Ppary) and CCAAT/enhancerbinding protein alpha $(C / e b p \alpha)$.

For fibroblastic differentiation, cells were treated with DMEM supplemented with $20 \% \mathrm{FBS}, 50 \mathrm{U}-\mu \mathrm{g} / \mathrm{ml}$ penicillin-streptomycin, $50 \mathrm{ng} / \mathrm{ml}$ recombinant human connective tissue growth factors (CTGF; BioVendor, Brno, Czech Republic) and $50 \mu \mathrm{M}$ ascorbic acid, with medium changed every 3 days (pMSCs and eMSCs after CTGF induction were named $\mathrm{pFs}$ and ESC-derived fibroblasts (eFs), respectively). Growth factors in pFs and eFs were further measured every 5 days by enzyme-linked immunosorbent assays (ELISA) in triplicate. After the medium was removed by gentle aspiration using a vacuum manifold, the cells were then washed with PBS, and lysed with the addition of $1 \mathrm{ml}$ RIPA buffer for total protein extraction. The cells were removed by scraping, and transferred into $1.5 \mathrm{ml}$ conical tubes. The mixture was incubated on ice for $30 \mathrm{~min}$, with occasional vortexing. The cell extracts were then assayed using mouse EGF, FGF, IGF1, VEGF, PDGF $\alpha$, PDGF $\beta$, TGF $\alpha$, and TGF $\beta 1$ ELISA $^{\text {tw }}$ kits (Lian Shuo Biological, Shanghai, China) in accordance with the manufacturer's instructions. Subsequently, the OD450 $\mathrm{nm}$ value was measured with an enzyme-labeled instrument (Thermo Fisher Scientific). The expression levels of mouse fibroblasts (Fs) were used as controls.

Col-I, Col-III, tenacin-C (Tn-c), matrix metalloproteinase-1 (Mmp-1), Vimentin, and fibroblast-specific protein-1 (Fsp-1) expression was screened by quantitative real-time PCR 20 days after induction. The primer sequences and the fragment sizes are presented in Table 2. To further detect the marker of derived fibroblasts, immunofluorescent staining was performed for rat anti-Vimentin (BOSTER), mouse anti-cytokeratin, goat anti-FSP1, and COL-I (all from Santa Cruz Biotechnology). Fibroblasts derived from pESCs and ESCs were named pFs and eFs, respectively.

\section{Preparation of TESE}

To prepare TESE, $150 \mu \mathrm{l}$ of $10 \times$ DMEM was added into $1 \mathrm{ml}$ ice-cold collagen solution $(4 \mathrm{mg} / \mathrm{ml}$ type I collagen from rat tail dissolved in $0.1 \%$ acetic acid). After neutralization with $500 \mu \mathrm{l} 0.1 \% \mathrm{NaOH}$ solution, $100 \mu \mathrm{l}$ of cell suspension $\left(5 \times 10^{6}\right.$ cells $\left./ \mathrm{ml}\right)$ was added into the solution and mixed immediately. The whole operation was carried out on ice. The mixture was transferred into
Table 2 Primers of fibroblast phenotypic hallmark genes for quantitative real-time PCR

\begin{tabular}{|c|c|c|}
\hline Gene & Primers $\left(5^{\prime}-3^{\prime}\right)$ & Product (bp) \\
\hline \multirow[t]{2}{*}{$\mathrm{COH}-\mathrm{I}$} & TCTCCCCCAAGACACAGGAA & \multirow[t]{2}{*}{103} \\
\hline & GCTGGGTAGGGAAGTAGACG & \\
\hline \multirow[t]{2}{*}{ Col-III } & ACTGTCCCACGTAAGCACTG & \multirow[t]{2}{*}{106} \\
\hline & CAGGAGGGCCATAGCTGAAC & \\
\hline \multirow[t]{2}{*}{$T n-c$} & CCTACTGTCACGCGTCTCTC & \multirow[t]{2}{*}{112} \\
\hline & AAGCCACAACGAGTTCCCAA & \\
\hline \multirow[t]{2}{*}{ Mmpl } & GAGCCACAGATGAGCACAGA & \multirow[t]{2}{*}{103} \\
\hline & AATCTGAACGCTCGCAGTGA & \\
\hline \multirow[t]{2}{*}{ vimentin } & CGCTCCTACGATTCACAGCC & \multirow[t]{2}{*}{189} \\
\hline & TGTGGACGTGGTCACATAGC & \\
\hline \multirow[t]{2}{*}{ Fsp 1} & СTTCCTGTCCTGCATTGCCA & \multirow[t]{2}{*}{112} \\
\hline & GGCAAACTACACCCCAACAC & \\
\hline
\end{tabular}

dishes $(d=35 \mathrm{~mm}$; Fisher Scientific, Pittsburgh, PA, USA) and then incubated at $37{ }^{\circ} \mathrm{C}$ and $5 \% \mathrm{CO}_{2}$ for gelling. Twenty-four hours later, $2 \mathrm{ml}$ DMEM was added, and the TESE was cultured for another 2 days before use [18]. We prepared TESE from $\mathrm{pFs}$, eFs, and Fs, and collagen gel without cells acted as control.

\section{TESE grafting onto mouse skin defects}

Twenty BALB/c mice were purchased from the Experimental Animal Center of The Fourth Military Medical University and treated in accordance with the guidelines provided by the Institutional Ethics Committee of Northwest University. Mice were anesthetized by intraperitoneal injection of pentobarbital sodium $(20 \mathrm{mg} / \mathrm{kg}$ body weight). Then $8 \%$ sodium sulfate was used to depilate the wounding area of animals (instead of shaving) 24 hours before wounding, to ensure synchronization of hair growth. A circular full-thickness 1.5 -cm-diameter skin defect was created on the back of each mouse using a biopsy punch $(15 \mathrm{~mm}$; purchased from Shanghai LZQ Precision Tool Technology Co., Ltd, Shanghai, China). TESE grafts derived from $\mathrm{pFs}$, eFs, Fs, and control $(n=5$ for each group) were implanted onto the skin defects. Grafts were covered with vaseline gauze and adhesive bandages for 3 days. Animal behavior and wounds were monitored throughout the experiment. Images were recorded at days $0,3,6,9,12,15$, and 18 post operation with a digital camera (Canon, Japan) to visualize the wound. The wound area was measured by tracing the wound margin and calculated using Image-Pro Plus Software (Media Cybernetics LP, Silver Spring, MD, USA). Investigators measuring samples were blind to groups and treatment. The wound closure percentage was calculated as follows: 
(Original defect area - actual defect area) / original defect area $\times 100 \%$

Animals were sacrificed at day 18 , and the regenerated skin specimens (including dermis and epidermis) were fixed in $10 \%$ buffered formalin for paraffin embedding. Sections were cut at $7 \mu \mathrm{m}$, deparaffinized, and stained with $H \& E$. Sections were also stained with a mouse Cytokeratin-14 antibody (1:200; Santa Cruz Biotechnology), and a secondary Alexa-Fluor 594-labeled goat antimouse IgG (1:500; Invitrogen) was used.

\section{Statistical analysis}

Data are expressed as mean \pm SD of at least three independent samples. Statistical comparisons between groups were performed with one-way ANOVA and twoway ANOVA analysis. $p<0.05$ and $p<0.01$ were considered significant.

\section{Results}

pESCs exhibit properties similar to the pluripotent J1-ESC line

ESCs and pESCs could form compact groups and proliferate actively (Fig. 1a). They expressed high levels of pluripotency gene markers, including NANOG, OCT3/4, and undifferentiated state marker SSEA-1 (Fig. 1b). Four weeks after injection of pESC and ESC suspension, tumor blocks could be observed on the back of the nude mice. Histological observation revealed that the newly formed teratomas contained three germ layers of epidermis (ectoderm), cartilage (mesoderm), and gut epithelium (endoderm) (Fig. 1c). These results demonstrated that pESCs exhibit similar fundamental properties to the well-characterized pluripotent J1-ESC line.

\section{pESCs are capable of differentiating into ectodermal,} endodermal, and mesodermal cells in vitro

pESCs and normal J1 ESCs formed EBs after 5 days of suspension culture. The immunofluorescent staining of EBs is shown in Fig. 2a. SSEA-1 expression was undetectable, demonstrating the initiation of differentiation. In addition, cytokeratin (ectoderm), CD73 (mesoderm), and CD151 (endoderm) expression became detectable. Gene expression profiles of EBs under adherent culture conditions revealed the programmed expression pattern related to the differentiation from ectodermal, mesodermal, and endodermal lineages, successively. The Nestin gene expression involved in ectoderm increased progressively 5 days after and declined 15 days after EB plating (Fig. 2c). The expression of mesodermal genes Snail1, Hand1, and Gata2 also upregulated progressively, which peaked at 10 days of pESC-EB plating and at 15 days of ESC-EB plating (Fig. 2c). This was followed by expression of the endoderm-specific gene $A f p$, peaking at 15 days after plating. Pluripotent marker Oct3/4 expression decreased rapidly at 5 days, and was almost undetectable at 15 days (Fig. 2c). The expression profile and level of genes in EBs of pESCs were similar to those of ESCs. Collectively, these data indicated that EBs from pESCs contained differentiated cells of all three germ layers and could be expanded during adherent culture.

\section{Enrichment and characterization of pMSCs}

Spindle-shaped cells could migrate from EBs 8-10 days after plating. When cultured in MSC medium in high density for 5-6 passages, cells derived from EBs exhibited fibroblastic morphology (Fig. 2b). The formation of MSCs is the intermediate stage during the process of ESC differentiation. Hence, we enriched eMSCs and pMSCs, which could be subcultured for up to 10 passages without obvious morphological changes. FACS analysis confirmed the positive expression of CD29, CD44, and CD73, particularly, with more than $95 \%$ of cells expressing CD73 (mesodermal marker) (Fig. 3b).

MSCs are functionally characterized by their ability to differentiate into mesenchymal tissues including bone, cartilage, and fat. Therefore, we tested whether pMSCs and eMSCs have the same potential. Cells of passage 5 were subjected to osteogenic, chondrogenic, and adipogenic differentiation in vitro using the standard protocol to confirm multilineage differentiation capability. Strong staining for Von Kossa and Alizarin Red staining 21 days after induction demonstrated calcium deposition in the matrix (Fig. 3c), together with upregulation of Alp and Ocn expression, indicating that pMSCs and eMSCs had osteogenic potential (Fig. 3d).

After chondrogenetic induction by TGF- $\beta 1$ and IGF for 21 days, strong staining for Safranin O could be observed around cells, indicating specific ECM of proteoglycan secretion and deposition. Typical mirror image cells were embedded in the matrix, verifying the chondrogenic lineage differentiation of these cells (Fig. 3c). Chondrogenic differentiation was also confirmed by the unregulated gene expression of Col-II and aggrecan, two components of ECM selectively expressed by chondrocytes, using RT-PCR (Fig. 3d).

Adipocytic differentiation of pMSCs and eMSCs was induced under conditions described previously. Appearance of cells harboring fat granules could be observed after induction for 14 days in culture, which is positive for Oil Red O staining (Fig. 3c). At the same time, increased expression of Ppary and C/ebpo, markers of adipocytic differentiation, was found upregulated during the process (Fig. 3d). Collectively, these results demonstrated that pMSCs and eMSCs have the multilineage differentiation capacity, and could be directed to differentiate into bone, cartilage, and fat. 

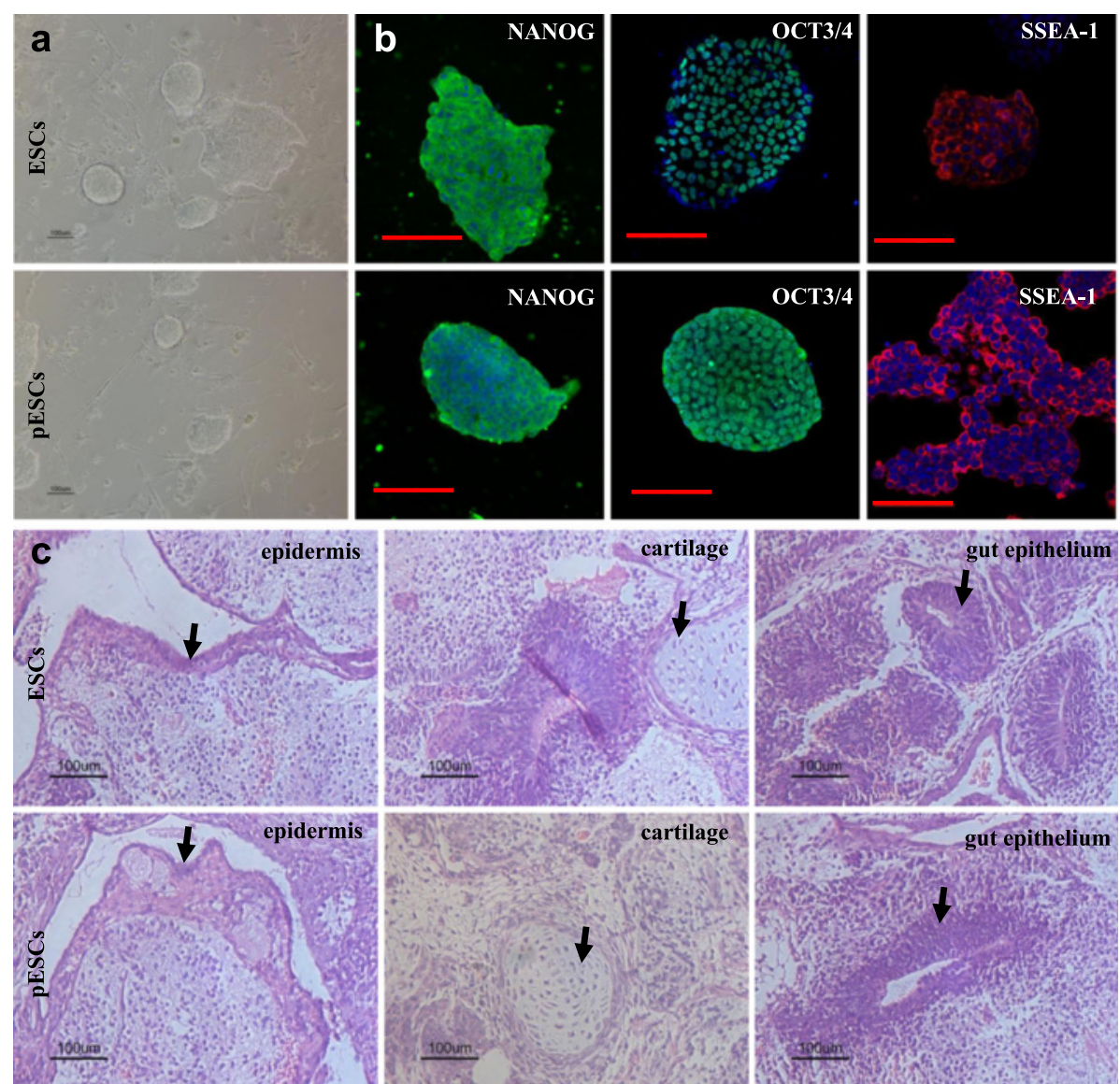

Fig. 1 pESCs exhibit properties similar to the pluripotent J1-ESC line. a Morphological observations of pESCs and ESCs under phase-contrast microscopy. $\mathbf{b}$ Immunocytochemistry staining of embryonic stem cell markers for pESCs and ESCs. c H\&E staining of teratoma sections from the pESCs and ESCs. The staining revealed that pESCs and ESCs possessed the capacity to generate epidermis, cartilage, and gut epithelium tissue in vivo. Bars $=100 \mu \mathrm{m}$. ESC embryonic stem cell, pESC parthenogenetic embryonic stem cell

\section{Fibroblastic differentiation of pMSCs}

As paracrine of growth factors is critical to skin regeneration, we compared the secretory profile of eFs, pFs, and Fs for selected growth factors. ELISA results revealed that $\mathrm{pFs}$ and eFs expressed similar elevated levels of growth factors including EGF, FGF, IGF1, TGF $\alpha$, TGF $\beta 1$, PDGF $\alpha$, and PDGF $\beta$ after induction with CTGF. Both pFs and eFs expressed a higher level of PDGF $\alpha$ (15 days after induction) and a lower level of FGF than Fs. Notably, the expression of EGF in eFs was significantly higher than that in pFs and Fs (15 and 20 days after induction) (Fig. 4a).

Quantitative real-time PCR detection indicated that after 20 days of treatment with $50 \mathrm{ng} / \mathrm{ml}$ CTGF, the expression of fibroblast phenotypic hallmarks including Col-I, Col-III, Tn-c, Mmp1, vimentin, and Fsp1 increased drastically in pFs and eFs (Fig. 4b). Morphological appearances of fibroblasts derived from pMSCs and eMSCs are shown in Fig. 4c. Immunofluorescent staining further demonstrated that these cell were positive for VIMENTIN, FSP1, and COL-I, but negative for CK (Fig. 4d).

\section{TESE from pFs promote mouse wound healing in vivo}

Gross appearance of TESE prepared from $\mathrm{pFs}$ is shown in Fig. 5c. Phase-contrast microscope observation indicated that cells were homogeneously distributed in the collagen gels and displayed a rounded morphology (Fig. 5a). Viable cells stained green could be noticed after CFDA labeling (Fig. 5b), indicating TESE could be generated from $\mathrm{pFs}$ and eFs.

All of the animals survived and no visible inflammation occurred during the process of wound healing. Gross inspections showed an increasing reduction in the area of the defects in all groups during the experiment and were digitally recorded on days $0,3,6,9,12,15$, and 18 after TESE grafting (Fig. 5d). As shown in Fig. 5e, the wound repair rate after different TESE grafting was 

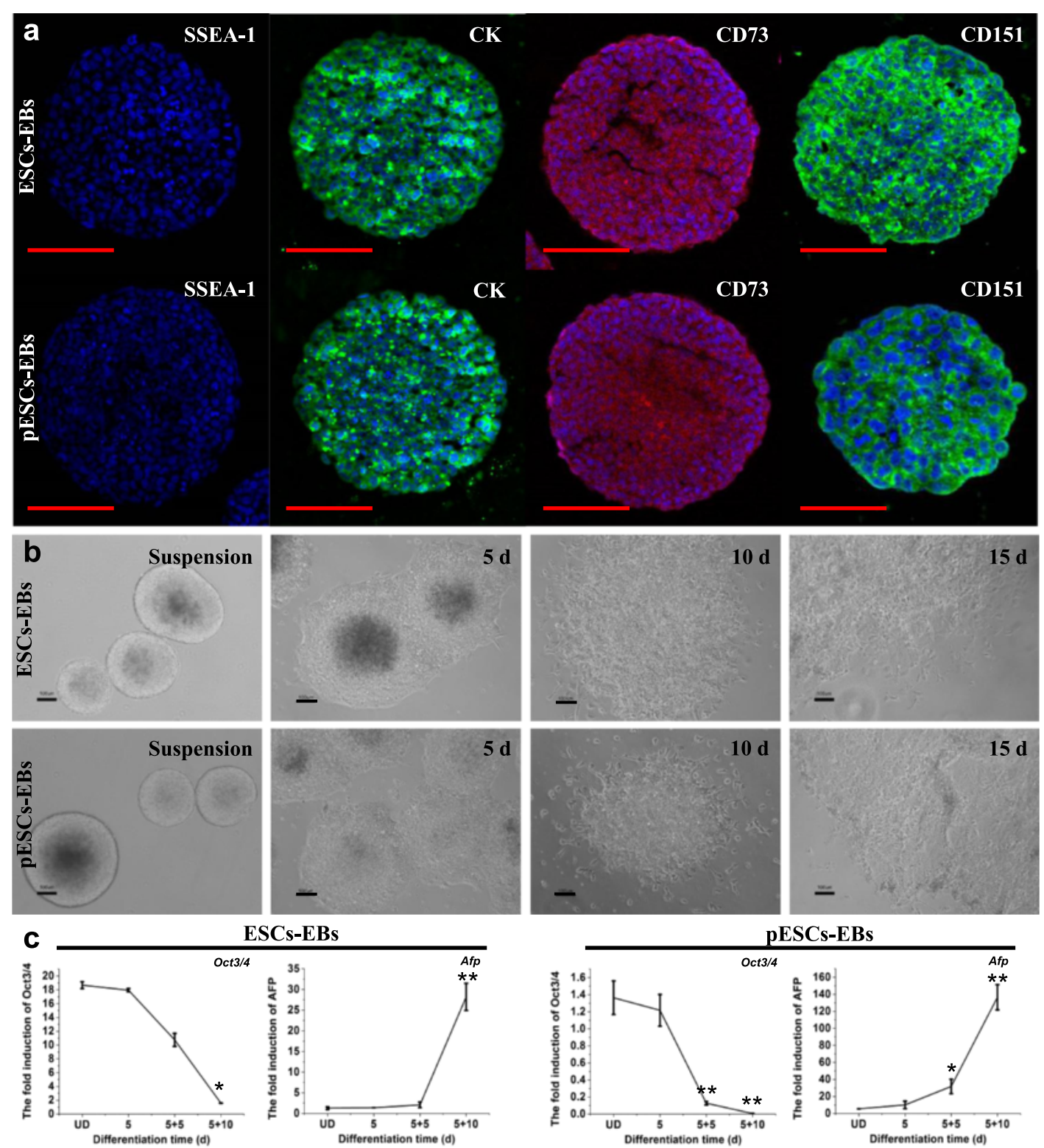

ESCs-EBs
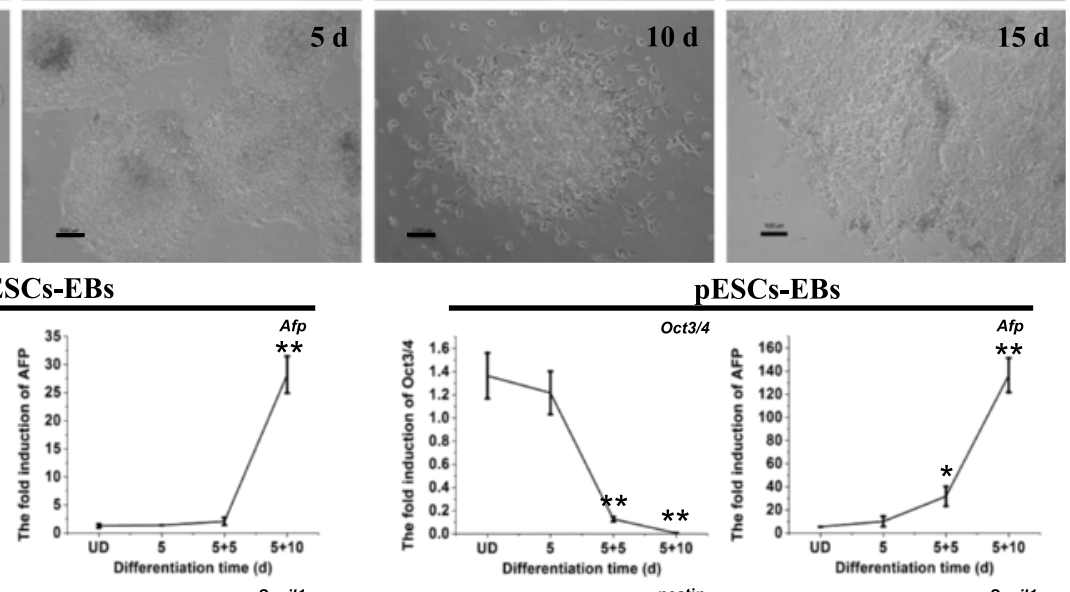

pESCs-EBs
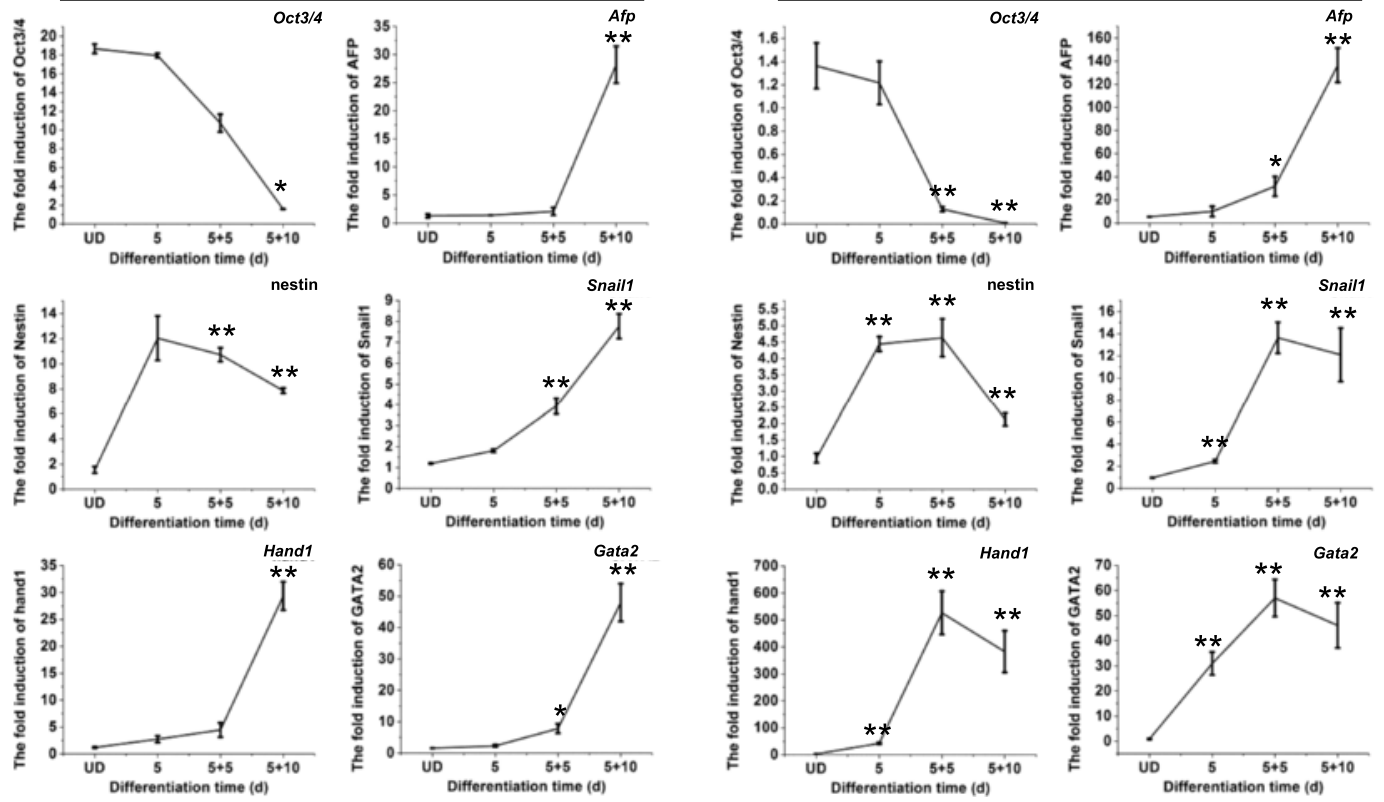

Fig. 2 (See legend on next page.) 
(See figure on previous page.)

Fig. 2 Characteristics of EB differentiation. a EB immunofluorescent staining of undifferentiated state marker SSEA-1 and surface antigens, including cytokeratin (CK), CD73, and CD151. Cell nuclei were stained with DAPI. Bars $=100 \mu \mathrm{m}$. b Morphological appearance of pESC-derived and ESC-derived EBs and outgrowths of EBs. Bars = $100 \mu \mathrm{m}$. c Expression of Oct3/4 (stemness), nestin (ectoderm), Afp (entoderm), and mesoderm markers Snai1, Hand1, and Gata2 in pESC-derived and ESC-derived EB outgrowths. ${ }^{*} p<0.05$, ${ }^{* *} p<0.01$ vs undifferentiated (UD) cells. Each experiment was repeated three times. EB embryoid body, ESC embryonic stem cell, pESC parthenogenetic embryonic stem cell

quantitatively measured. The collagen gel without cells showed the lowest capacity for the repair of the skin defect and by day 15 the overall wound repair rate was $69.1 \%$, which was significantly lower compared with the other groups $(p<0.05)$, and the skin defects were reepithelialized by day 18. The F-TESE group exhibited the highest wound closure rate and most of the skin defect was repaired by day 15 ( $80.5 \%$ wound closure rate). Similar to the F-TESE group, wound closure rates were $80.1 \%$ and $77.0 \%$ in the pF-TESE and eF-TESE group, respectively, and there was no significant difference compared with the F-TESE group $(p>0.05)$ (Tables 3 and 4). Skin specimens was harvested at day 18 and processed for histological examination to detect the quality of the newly repaired tissue. Cytokeratin-14 immunostaining showed that cytokeratins existed in all groups, indicating that the skin defects have been re-epithelialized 18 days post operation. Three cell seeding groups (pFs, eFs, and Fs seeded into collagen gel) showed better skin structure and stronger CK-14 staining (Fig. 6).

\section{Discussion}

Recent progress in regenerative medicine and tissue engineering has focused on the application of ESC derivatives to improve regeneration of targeted tissues $[19,20]$, due to their unlimited proliferative capacity and the potential to give rise to a variety of differentiated cell types. Several studies have so far reported the successful preparation of skin equivalents using keratinocytes or fibroblasts derived from ESCs. However, political and ethical limitations may hinder the application of ESCs and their derivatives. Induced pluripotent stem (iPS) cells obtained by reprogramming of somatic cell have also drawn much attention [21], and directed differentiation of iPS cells into

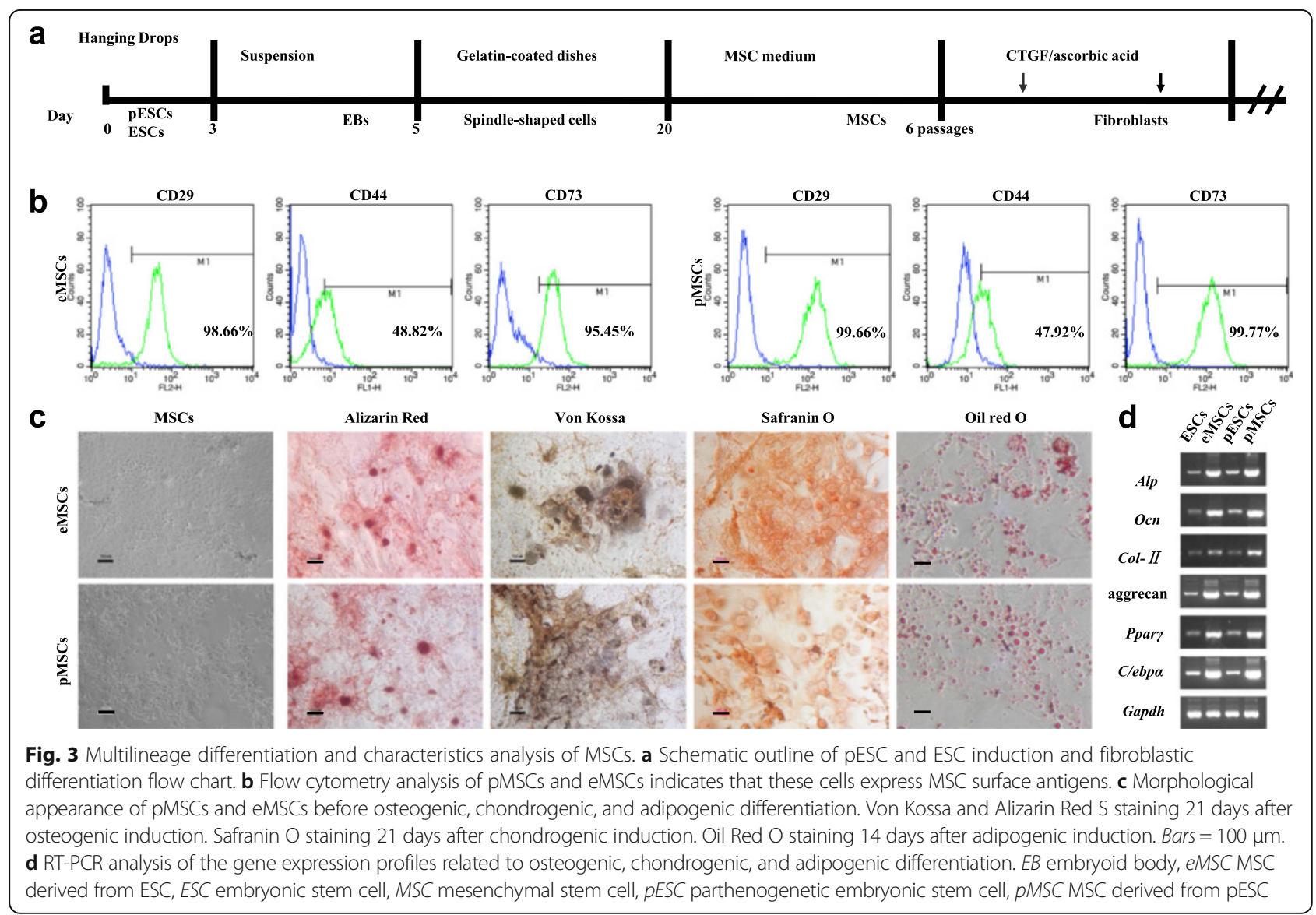




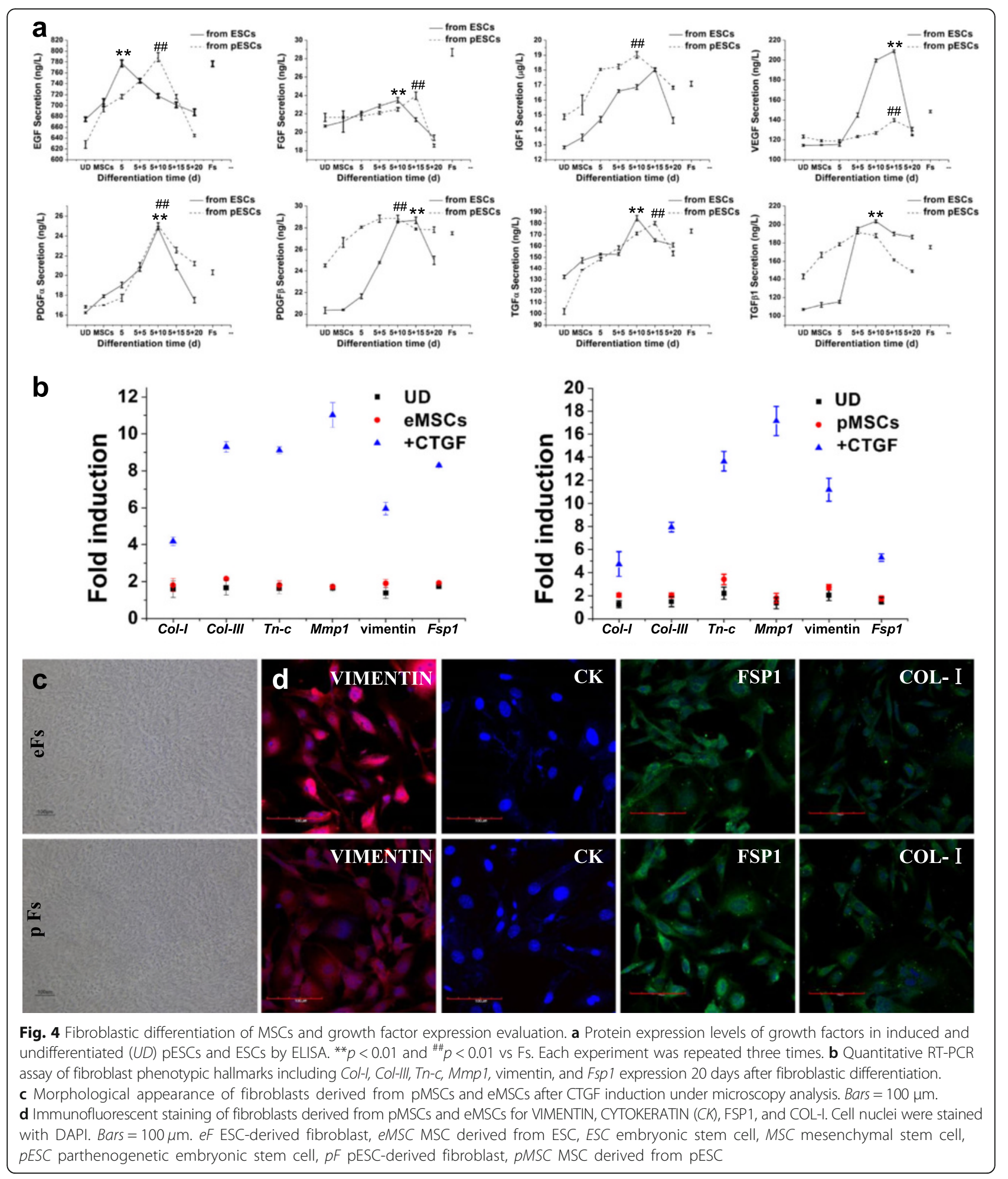

$>$ several cell lineages have also been reported in detail [22, 23]. But the major limitations for iPS cells is timely allocation (usually within weeks to several months), which make them inapplicable for the treatment of acute disease conditions including large burns, heart failure, bone, and cartilage injuries.

pESCs are derived from the blastocysts of chemically activated and subsequently developed oocytes. Because 


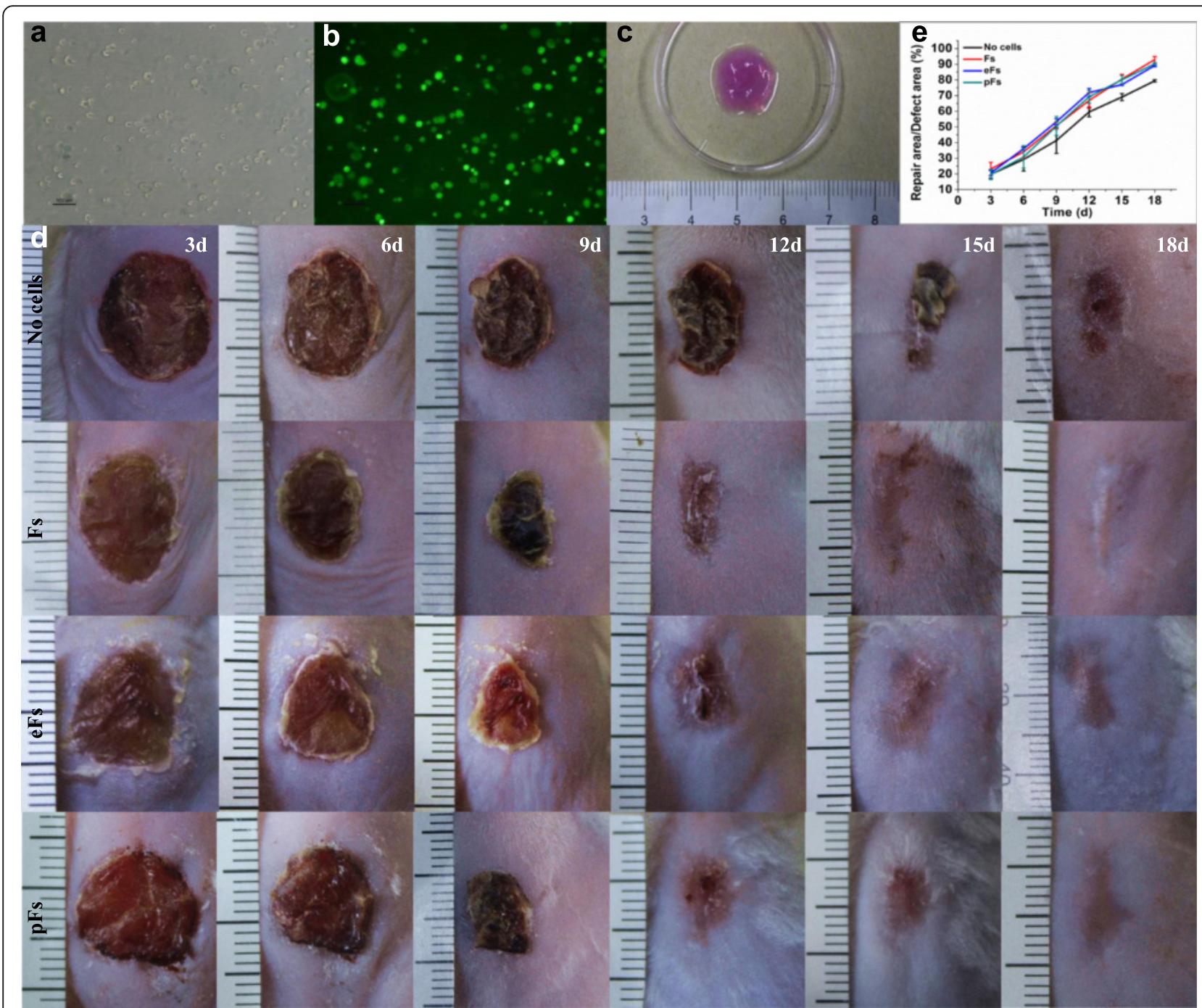

Fig. 5 Preparation of TESE and grafting onto mice. a Homogeneous cell encapsulation in the collagen gels. Bars= $100 \mu$ m. b CFDA labeling shows the high viability of embedded cells in the collagen gels. Bars $=100 \mu \mathrm{m}$. c Gross appearance of prepared TESE before use. $\mathbf{d}$ Gross appearance of skin defect repair. e Mean wound closure percentage for each group in a time manner. Error bars represent SDs, $n=5$ for each group. Statistical results are presented in Table 4. eF embryonic stem cell-derived fibroblast, $F$ mouse fibroblast, $p F$ parthenogenetic embryonic stem cell-derived fibroblast

Table 3 Wound repair rate (\%) after different TESE grafting in a time manner

\begin{tabular}{lllllll}
\hline & 3 days & 6 days & 9 days & 12 days & 15 days & 18 days \\
\hline No cell & $19.77 \pm 2.46$ & $29.31 \pm 7.46$ & $41.34 \pm 8.22$ & $59.57 \pm 3.10$ & $69.05 \pm 2.26$ & $79.38 \pm 0.76$ \\
Fibroblasts & $23.14 \pm 4.28$ & $34.09 \pm 3.81$ & $50.87 \pm 2.34$ & $66.85 \pm 4.98$ & $80.5 \pm 3.10$ & $92.92 \pm 1.96$ \\
eMSCs & $20.71 \pm 1.66$ & $36.12 \pm 1.02$ & $53.32 \pm 1.98$ & $71.91 \pm 2.63$ & $77.01 \pm 0.52$ & $89.20 \pm 0.71$ \\
pMSCs & $19.70 \pm 3.23$ & $30.86 \pm 7.14$ & $50.59 \pm 6.03$ & $69.25 \pm 4.12$ & $80.06 \pm 2.74$ & $90.20 \pm 0.78$ \\
\hline
\end{tabular}

Data presented as mean \pm SD eMSC mesenchymal stem cell derived from embryonic stem cell, pMSC mesenchymal stem cell derived from parthenogenetic embryonic stem cell, TESE tissueengineered skin equivalents 
Table 4 Statistics analysis of wound repair rate between groups 15 days after different TESE transplantation

\begin{tabular}{llll}
\hline & No cells & Fs & eFs \\
\hline Fs & $p<0.05$ & & \\
eFs & $p<0.05$ & $p>0.05$ & \\
pFs & $p<0.05$ & $p>0.05$ & $p>0.05$ \\
\hline
\end{tabular}

$F$ mouse fibroblast, eF embryonic stem cell-derived fibroblast, $p F$ parthenogenetic embryonic stem cell-derived fibroblast, TESE tissue-engineered skin equivalents

parthenogenetic blastocysts are not able to develop into an embryo, the ethical concerns relating to the application of ESCs derived from fertilized oocytes could be avoided [10]. Importantly, haploid identity of major histocompatibility complex (MHC) of pESCs may increase immune tolerance after allogeneic cell transplantation and decrease the number of cell lines needed for therapeutic cell banking [24-26]. One of the main challenges in using pESCs for regenerative medicine is the difficulty of directing pESC differentiation into the interested phenotype. In a pioneer study, Michel et al. induced pESC differentiation toward the cardiac lineage and tested its application in tissue-engineered heart repair [11]. The results showed that cardiomyocytes could be obtained to facilitate engineering of force-generating myocardium and demonstrated the utility of this technique in enhancing regional myocardial function after myocardial infarction. Importantly, their results also demonstrated the immunological acceptance of pESC allografts in related and unrelated recipients with matched MHC. We have successfully fabricated injectable adipose tissue with pESC-derived adipocytes [27].

In the current study, we aimed to determine whether pESCs could be directed to differentiate into fibroblasts in vitro, and to evaluate the application in tissueengineered skin defect repair. We first demonstrated that pESCs and ESCs had similar fundamental differentiation potential. The teratoma formation test demonstrated that both pESCs and ESCs could differentiate into epidermis (ectoderm), cartilage (mesoderm), and gut epithelium (endoderm) in vivo. Importantly, hyaline cartilage could be observed in the teratoma tissue after pESC injection, indicating that pESCs have strong potential to differentiate into mature mesenchymal tissue (Fig. 1). PCR and immunofluorescent observation demonstrated that cells in EBs could spontaneously differentiate into cells of three germ layers, as indicated by gene expression of nestin (ectoderm), Afp (endoderm), and Snail1, Hand1, and Gata2 (mesoderm) (Fig. 2). Interestingly, we found pESCEB outgrowth underwent earlier differentiation compared with ESC-EB. As indicated by RT-PCR assay, the expression of mesodermal genes from pESC-EB outgrowth peaked at 10 days after plating, while expression peaked at 15 days after ESC-EB plating (Fig. 2c). In accordance with

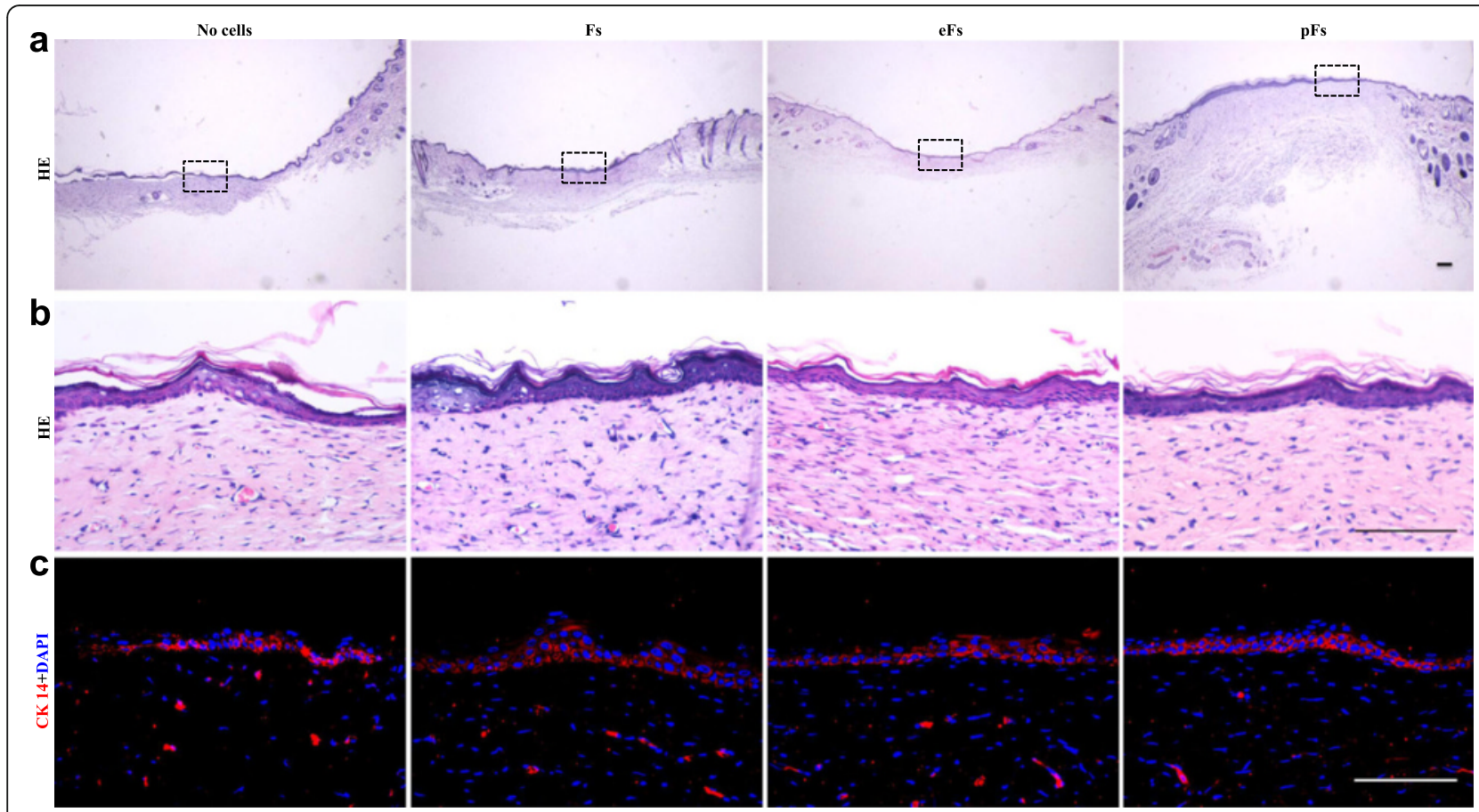

Fig. 6 H\&E and immunofluorescent staining of repaired skin tissues 18 days after TESE grafting onto mouse skin defects. a Low-power and b high-power magnificent H\&E staining of repaired skin tissues 18 days after grafting. Bars $=100 \mu \mathrm{m}$. c Immunofluorescent staining of repaired skin tissues 18 days after grafting for cytokeratin-14 (CK 14). Cell nuclei were stained with DAPI. Bars $=100 \mu \mathrm{m}$. ef embryonic stem cell-derived fibroblast, $F$ mouse fibroblast, $p F$ parthenogenetic embryonic stem cell-derived fibroblast 
this result, the expression of Oct3/4 in pESC-EB outgrowth was much lower than that of ESCs-EBs at 10 days of plating.

We then directed pESCs to differentiate into fibroblasts with stepwise induction. Adherent culture is critical to obtain targeted cell numbers for application. After adherent culture of EBs for 10 or 15 days, MSC culture medium was applied and cells were subcultured for 5-6 passages in high density to enrich MSCs from EB derivatives. Flow cytometry detection indicated that pMSCs and eMSCs expressed MSC markers (Fig. 3). Multipotent differentiation investigation showed that the expanded cell populations could be induced to differentiate into osteogenic, chondrogenic, and adipogenic lineages (Fig. 3c, d), respectively, which were in agreement with the results from Hwang et al. [28].

It has been reported that adult MSCs can also differentiate into fibroblastic lineage under the induction of CTGF [29]. We next tested whether pMSCs and eMSCs possess this potential under the conditions described previously. After treatment with CTGF, fibroblast phenotypic hallmarks drastically increased, including Col-I, Col-III, Tn-c, $M m p 1$, vimentin, and Fsp1 (Fig. 4b, c). Importantly, these cells also expressed a high level of growth factors after induction, which is critical for skin defect repair and wound healing. Compared with normal fibroblasts, pFs exhibited a similar or higher expression level of EGF, IGF1, VEGF, TGF $\alpha$, TGF $\beta 1$, PDGF $\beta$, and PDGF $\alpha$ (Fig. 4a).

Finally we tested pF-derived and eF-derived TESE for the repair of skin defects. In accordance with our hypothesis, pFs were similar to Fs and eFs not only phenotypically but also in functional terms. In-vivo experiments indicated that pF-derived TESE are as efficient as normal fibroblasts and eF-derived TESE for the re-epidermalization of the skin defects (Fig. 5 d, e). More than $80 \%$ of skin defects $(80.06 \pm 2.74)$ were repaired 15 days after $\mathrm{pF}$ derived TESE transplantation (Table 3).

\section{Conclusions}

One of our key findings in the current study is that pESCs could be directed into a fibroblastic lineage via the middle stage of MSCs, facilitating for tissue-engineered skin defect repair. pMSCs have strong potential to differentiate into osteogenic and chondrogenic lineages, suggesting that pMSCs are also facilitated for bone and cartilage tissue engineering. Compared with ESCs and iPS cells, pESCs have ethical, immunological, and technical (no genetic manipulation required) advantages. Collectively, these characteristics, together with the ease and high efficiency of directed differentiation, warrant pESCs as an optimizing source for tissue engineering and regenerative medicine.

\section{Abbreviations}

ALP: Alkaline phosphates; C/EBPa: CCAAT/enhancer-binding protein alpha; EB: Embryoid body; ECM: Extracellular matrix; eMSCs: MSCs derived from ESCs; ESC: Embryonic stem cell; FSP1: Fibroblast-specific protein-1; MMP-

1: Matrix metalloproteinase-1; MSC: Mesenchymal stem cell;

OCN: Osteocalcin; pESC: Parthenogenetic embryonic stem cell; pMSCs: MSCs derived from pESCs; PPARY: Peroxisome proliferator-activated receptor gamma; TESE: Tissue-engineered skin equivalents

\section{Acknowledgements}

This work was supported by the National Natural Science Foundation of People's Republic of China (No. 31271026, 31300797, J1210063), and the Shaanxi Province and Ministry of Education Natural Science Foundation (No. 2013JQ4022, 13JS107)

\section{Funding}

Not applicable.

\section{Availability of data and materials}

The datasets supporting the conclusions of this article are included within the article.

\section{Authors' contributions}

RY, CJH, YL, and LW contributed to the study design, study performance, data collection, and preparation of the manuscript. LWG, SM, YXR, and WL contributed to the study performance, data analysis and interpretation, and preparation and revision of the manuscript. CFL contributed to the study design, preparation, and revision of the manuscript. RY and $\mathrm{CJH}$ contributed equally to this work and should be considered coauthors. All authors approved the final version of this manuscript.

\section{Competing interests}

The authors declare that they have no competing interests.

\section{Consent for publication}

Not applicable.

\section{Ethical approval and consent to participate}

All of the mice in our study were treated in accordance with the guidelines provided by the Institutional Ethics Committee of Northwest University and the study was approved by the Ethics Committee.

Received: 28 April 2016 Revised: 4 August 2016

Accepted: 6 September 2016 Published online: 22 October 2016

References

1. Böttcher-Haberzeth S, Biedermann T, Reichmann E. Tissue engineering of skin. Burns. 2010;36:450-60.

2. O'Connor N, Mulliken J, Banks-Schlegel S, Kehinde O, Green H. Grafting of burns with cultured epithelium prepared from autologous epidermal cells. Lancet. 1981;1:75-78.

3. Reubinoff BE, Pera MF, Fong CY, Trounson A, Bongso A. Embryonic stem cell lines from human blastocysts: somatic differentiation in vitro. Nat Biotechnol. 2000;18:399-404.

4. Cerqueira MT, Marques AP, Reis RL. Using stem cells in skin regeneration: possibilities and reality. Stem Cells Dev. 2012;21:1201-14.

5. Shamis Y, Hewitt KJ, Carlson MW, Margvelashvilli M, Dong S, Kuo CK, Daheron L, Egles C, Garlick JA. Fibroblasts derived from human embryonic stem cells direct development and repair of 3D human skin equivalents. Stem Cell Res Ther. 2011;2:10.

6. Diekman BO, Christoforou N, Willard VP, Sun H, Sanchez-Adams J, Leong KW, Guilak F. Cartilage tissue engineering using differentiated and purified induced pluripotent stem cells. Proc Natl Acad Sci U S A. 2012;109:19172-7.

7. Kang X, Xie Y, Powell HM, James Lee L, Belury MA, Lannutti JJ, Kniss DA. Adipogenesis of murine embryonic stem cells in a three-dimensional culture system using electrospun polymer scaffolds. Biomaterials. 2007;28:450-8.

8. Marolt D, Campos IM, Bhumiratana S, Koren A, Petridis P, Zhang G, Spitalnik PF, Grayson WL, Vunjak-Novakovic G. Engineering bone tissue from human embryonic stem cells. Proc Natl Acad Sci U S A. 2012;109:8705-9. 
9. Guenou H, Nissan X, Larcher F, Feteira J, Lemaitre G, Saidani M, Del Rio M, Barrault CC, Bernard FX, Peschanski M, Baldeschi C, Waksman G. Human embryonic stem-cell derivatives for full reconstruction of the pluristratified epidermis: a preclinical study. Lancet. 2009;374:1745-53.

10. Kim K, Lerou P, Yabuuchi A, Lengerke C, Ng K, West J, Kirby A, Daly MJ, Daley GQ. Histocompatible embryonic stem cells by parthenogenesis. Science. 2007;315:482-6.

11. Didie M, Christalla P, Rubart M, Muppala V, Doker S, Unsold B, El-Armouche A, Rau T, Eschenhagen T, Schwoerer AP, Ehmke H, Schumacher U, Fuchs S, Lange C, Becker A, Tao W, Scherschel JA, Soonpaa MH, Yang T, Lin Q, Zenke M, Han DW, Scholer HR, Rudolph C, Steinemann D, Schlegelberger B, Kattman S, Witty A, Keller G, Field LJ, Zimmermann WH. Parthenogenetic stem cells for tissue-engineered heart repair. J Clin Invest. 2013;123:1285-98.

12. Lampton PW, Crooker RJ, Newmark JA, Warner CM. Expression of major histocompatibility complex class I proteins and their antigen processing chaperones in mouse embryonic stem cells from fertilized and parthenogenetic embryos. Tissue Antigens. 2008;72:448-57.

13. Espejel S, Eckardt S, Harbell J, Roll GR, McLaughlin KJ, Willenbring H. Brief report: Parthenogenetic embryonic stem cells are an effective cell source for therapeutic liver repopulation. Stem Cells. 2014;32:1983-8.

14. Turovets N, Fair J, West R, Ostrowska A, Semechkin R, Janus J, Cui L, Agapov V, Turovets I, Semechkin A, Csete M, Agapova L. Derivation of high-purity definitive endoderm from human parthenogenetic stem cells using an in vitro analog of the primitive streak. Cell Transplant. 2012;21:217-34.

15. Li WB, Zhang YS, Lu ZY, Dong LJ, Wang FE, Dong R, Li XR. Development of retinal pigment epithelium from human parthenogenetic embryonic stem cells and microRNA signature. Invest Ophthalmol Vis Sci. 2012;53:5334-43.

16. Isaev DA, Garitaonandia I, Abramihina TV, Zogovic-Kapsalis T, West RA, Semechkin AY, Muller AM, Semechkin RA. In vitro differentiation of human parthenogenetic stem cells into neural lineages. Regen Med. 2012;7:37-45.

17. Livak KJ, Schmittgen TD. Analysis of relative gene expression data using real-time quantitative $P C R$ and the 2(-Delta Delta $C(T)$ ) method. Methods. 2001;25:402-8.

18. Chen F, Zhang W, Wu W, Jin Y, Cen L, Kretlow JD, Gao W, Dai Z, Wang J, Zhou G, Liu W, Cui L, Cao Y. Cryopreservation of tissue-engineered epithelial sheets in trehalose. Biomaterials. 2011;32:8426-35.

19. Karlsson C, Emanuelsson K, Wessberg F, Kajic K, Axell MZ, Eriksson PS, Lindahl A, Hyllner J, Strehl R. Human embryonic stem cell-derived mesenchymal progenitors - potential in regenerative medicine. Stem Cell Res. 2009;3:39-50.

20. Brederlau A, Correia AS, Anisimov SV, Elmi M, Paul G, Roybon L, Morizane A, Bergquist F, Riebe I, Nannmark U, Carta M, Hanse E, Takahashi J, Sasai Y, Funa K, Brundin P, Eriksson PS, Li JY. Transplantation of human embryonic stem cell-derived cells to a rat model of Parkinson's disease: effect of in vitro differentiation on graft survival and teratoma formation. Stem Cells. 2006;24:1433-40.

21. Takahashi K, Yamanaka S. Induction of pluripotent stem cells from mouse embryonic and adult fibroblast cultures by defined factors. Cell. 2006;126:663-76.

22. Kondo Y, Yoshihashi S, Mimori K, Ogihara R, Kanehama Y, Maki Y, Enosawa S, Kurose K, Iwao T, Nakamura K, Matsunaga T. Selective culture method for hepatocyte-like cells differentiated from human induced pluripotent stem cells. Drug Metab Pharmacokinet. 2014;29:407-13.

23. Masumoto H, Ikuno T, Takeda M, Fukushima H, Marui A, Katayama S, Shimizu T, Ikeda T, Okano T, Sakata R, Yamashita JK. Human iPS cellengineered cardiac tissue sheets with cardiomyocytes and vascular cells for cardiac regeneration. Sci Rep. 2014;4:6716.

24. Hohlfeld J, de Buys Roessingh A, Hirt-Burri N, Chaubert P, Gerber S, Scaletta C, Hohlfeld P, Applegate LA. Tissue engineered fetal skin constructs for paediatric burns. Lancet. 2005;366:840-2.

25. Nakatsuji N, Nakajima F, Tokunaga K. HLA-haplotype banking and iPS cells. Nat Biotechnol. 2008;26:739-40.

26. Taylor CJ, Bolton EM, Pocock S, Sharples LD, Pedersen RA, Bradley JA. Banking on human embryonic stem cells: estimating the number of donor cell lines needed for HLA matching. Lancet. 2005;366:2019-25.

27. Liu W, Yang X, Yan X, Cui J, Sun M, Rao Y, Chen F. Directing parthenogenetic stem cells differentiate into adipocytes for engineering injectable adipose tissue. Stem Cells Int. 2014;2014:423635.
28. Hwang NS, Varghese S, Lee HJ, Zhang Z, Ye Z, Bae J, Cheng L, Elisseeff J. In vivo commitment and functional tissue regeneration using human embryonic stem cell-derived mesenchymal cells. Proc Natl Acad Sci U S A. 2008:105:20641-6.

29. Lee CH, Shah B, Moioli EK, Mao JJ. CTGF directs fibroblast differentiation from human mesenchymal stem/stromal cells and defines connective tissue healing in a rodent injury model. J Clin Invest. 2010;120:3340-9.

\section{Submit your next manuscript to BioMed Central and we will help you at every step:}

- We accept pre-submission inquiries

- Our selector tool helps you to find the most relevant journal

- We provide round the clock customer support

- Convenient online submission

- Thorough peer review

- Inclusion in PubMed and all major indexing services

- Maximum visibility for your research

Submit your manuscript at www.biomedcentral.com/submit
Ciomed Central 